\title{
The Effect of Position and Different Size of Radial Hole on Performance of Cannulated Pedicle Screw
}

\author{
F. A. Zakaria' ${ }^{1}$, R. Daud ${ }^{1}$, H. Mas Ayu' ${ }^{1}$, S. H. Tomadi ${ }^{1}$, M. S. Salwani ${ }^{1}$, Mohammed Rafiq Abdul Kadir ${ }^{2}$ \\ ${ }^{1}$ Faculty of Mechanical, Universiti Malaysia Pahang, 26600 Pekan, Pahang, Malaysia \\ ${ }^{2}$ Faculty of BioSciences \& Medical Engineering, Universiti Teknologi Malaysia, 81310 Skudai, Johor, Malaysia
}

\begin{abstract}
Cannulated Pedicle Screw (CPS) is the instrumentation that has been introduced in Biomedical field in order to stabilize the spine structure and also to enhance the pullout strength in osteoporotic patient. The cement is injected through the CPS which is flow from the screw head to the radial hole and then distributed around the CPS to give higher performance of pullout strength. However, the fracture still reported to happened around the radial hole. This paper is aim to focus on the effect of the position and different diameter of radial hole on the CPS. Three designs were constructed using SolidWork software where two of it are the current models whereas the third was the proposed design which the radial holes were position differently (skewed to each other) and its size is smaller than the current model, $1.0 \mathrm{~mm}$ and $1.5 \mathrm{~mm}$ respectively. The software used for Finite Element Analysis (FEA) is Ansys workbench 16.0. The Finite Element Models were verified with FEA result of the previous research. The FEA results of torsional stress for current and proposed design were then compared to obtain the maximum torque that both designs are able to resist before fracture. It can be concluded that the performance of CPS can be improved by the proposed design which is 2 radial hole skewed to each other and smaller radial hole diameter $(1.0 \mathrm{~mm})$ than the current cannulated pedicle screw $(1.5 \mathrm{~mm})$.
\end{abstract}

\section{Introduction}

The normal bone mineral densities is between -1 and above, low bone density also called as Osteopenia is in range -1 to -2.5 whereas -2.5 and below than that is in the category of Osteoporosis. The decreasing value of the bone mineral density decreased the holding strength of the bone. Thus, the normal pedicle screw is not suitable for the osteoporosis bones due to low holding strength. Cannulated pedicle screw (CPS) with cement augmented has been introduced as a solution for osteoporosis bones to increase the pullout strength [1].

Pullout strength of a pedicle screw is significantly correlated with the screw design whereas the more interface between screw and bone tissues can provide more pullout strength. To increase the interface, radial holes could be an option which allows bone growth through the holes. Mckoy et al. compared the pullout strengths of CPS with radial holes and normal pedicle screw on osteoporotic human vertebrae [2]. They found that radial holes had increased the amount of the cement exuded from the CPS, thus it caused pullout strength of CPS is 2.78 times higher than standard pedicle screw. Chen et al. found that the position of the radial hole primarily limited to the distal one third of the shaft to avoid the leakage of the cement into the spinal canal [3]. They proved that the performance of CPS is depends on the position of the radial holes but not on the number of the radial holes. They also found that the failure rate of CPS can be reduced by reducing the number of the radial hole. Although the effect of parameters of the radial holes (diameter and position of radial holes) on failure rate of CPS have been proof experimentally and numerically by several researchers [4-10], the optimum position and diameter of radial holes still becoming one of the gap in this research field. Thus, the aim of this paper is to propose the design optimization of cannulated pedicle screw which focuses more on optimization of diameter and position of radial holes.

\section{Methodology}

\subsection{Construction of Cannulated Pedicle Screw (CPS)}

The solid models of CPS were constructed and assemble by using Solidwork Software 2015. The geometry and the dimensions of the screw were followed the standard size of the cannulated pedicle screw. Three different 3D CPS were created where the first and second one is following the current design of CPS with different size and position of radial hole while another one is the proposed design. By referring to the research entitled 'Biomechanical Performance of Various Cement-Augmented Cannulated Pedicle Screw Design for Osteoporotic Bones' by Toga Tolunay et. al [1] and the 'Effect of different radial hole designs on pullout and structural strength of Cannulate 
Pedicle Screw' by Hsin-Chang Chen et al. [3], two current model of Cannulated Pedicle Screw was selected with higher strength compared to other and was constructed using Solidworks software:

i) CPS with 4 radial hole positioned $90^{\circ}$ to each other, descending in a counterclockwise direction according to the thread (figure 1).

ii) CPS with 2 radial hole row unilaterally (figure 2).

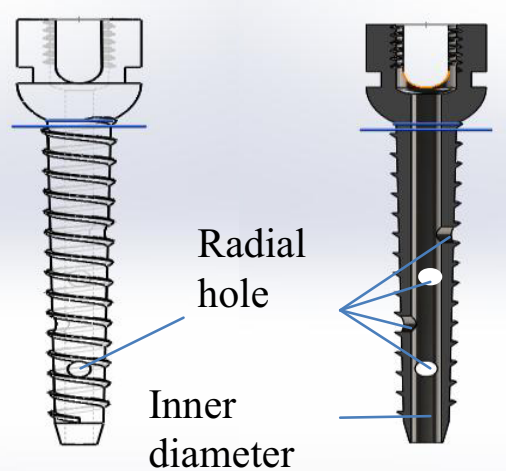

Figure 1. Front and sectional view of current model of CPS with 4 radial hole positioned to each other, descending in a counter clockwise direction according to the thread

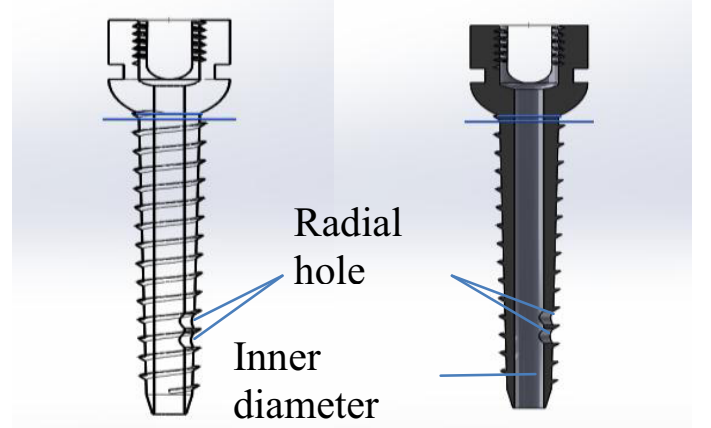

Figure 2. Front and sectional view of CPS with 2 radial hole row unilaterally.

The proposed design of the CPS is designed with different sizes and positions of the radial holes. By comparing the performance of CPS with different sizes and positions of radial holes, we obtained the optimum diameter is $1.0 \mathrm{~mm}$ and the optimum position of radial holes is skewed to each other (Figure 3).

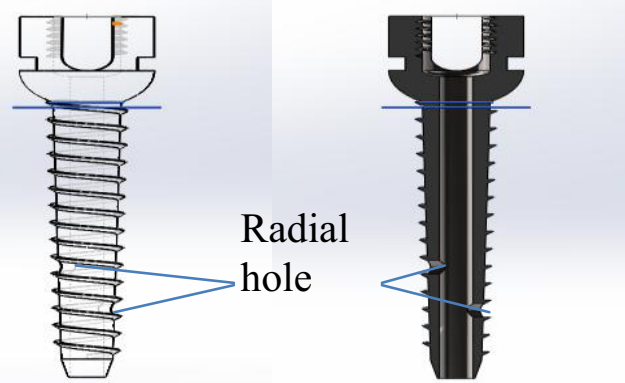

\subsection{Finite Element Analysis (FEA)}

The Finite Element Analysis (FEA) is conducted by FEA Engineering Software. Ansys Workbench 16. The material used is Titanium Alloy. In order to perform finite element analysis of each model, the model of the screw need to be saved in parasolid $x$. file in solidworks and then imported as the modeler in Ansys software. The geometry firstly need to be mesh before it is proceed into analysis. The finer the meshing size the precise the value of the Equivalent Stress (Von Mises Stress) also the longer the duration of the analysis to finished. The fine meshing size is shown in the Figure 4 below.

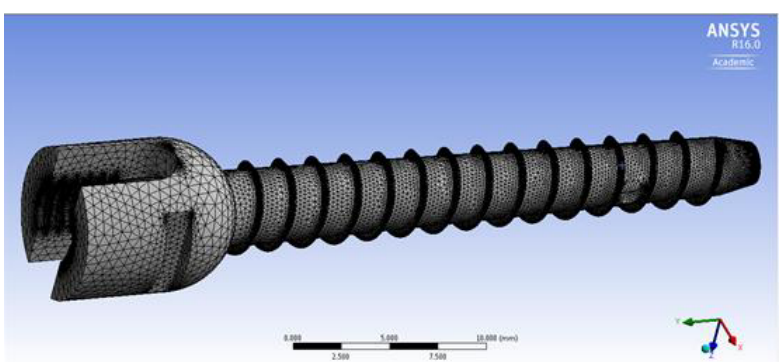

Figure 4. Meshing of the Cannulated Pedicle Screw using Ansys Software.

The boundary condition of the screw applied on the meshed model in order to results in stress analysis act on the screw. For the environment condition, the temperature is set $37{ }^{\circ} \mathrm{C}$ following the normal body temperature. To perform static structural of torsion test, as shown in Figure 5 below, the screw tip was completely fixed in all direction and an initial torque of $1.29 \mathrm{Nm}$ was applied to the body of the screw and was repeated in increment of $0.3 \mathrm{Nm}$ until the Von Mises stress approximately similar or approaching the yield stress. The yield stress was set at $790 \mathrm{MPa}$.

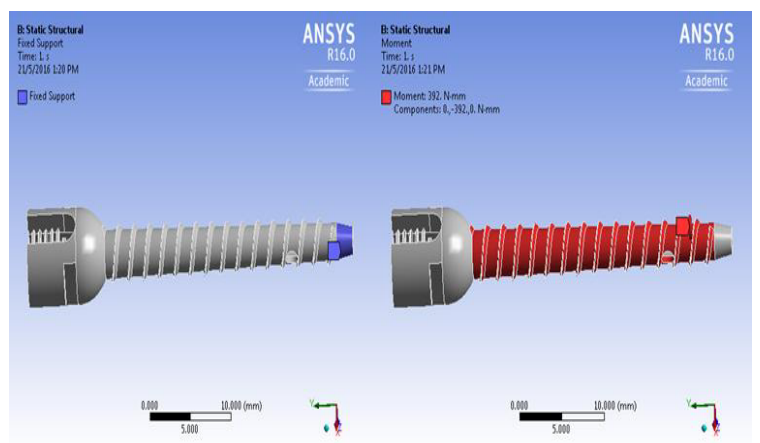

Figure 5. Fixed point applied on the screw tip and torque applied on the screw body.

Both proposed and current 3D results of analysis are compared to see either the proposed or the current design have the better performance. The comparison of both current and proposed design is based on the maximum stress that each of the cannulated screw can bear with the different torque applied without exceeding the yield stress of $790 \mathrm{MPa}$.

Figure 3. The proposed design with 2 radial hole positioned skewed to each other 


\section{Results and Discussion}

\subsection{Radial hole positioned $90^{\circ}$ to each other, descending counter clockwise according to the thread}

The results of equivalent stress that approaching yield stress obtained for this design is $770.47 \mathrm{MPa}$ with maximum allowable torque of $3.39 \mathrm{Nm}$. The stress focused around the radial hole which it means if the stress applied more than that can cause fracture around the radial hole (Figure 6).

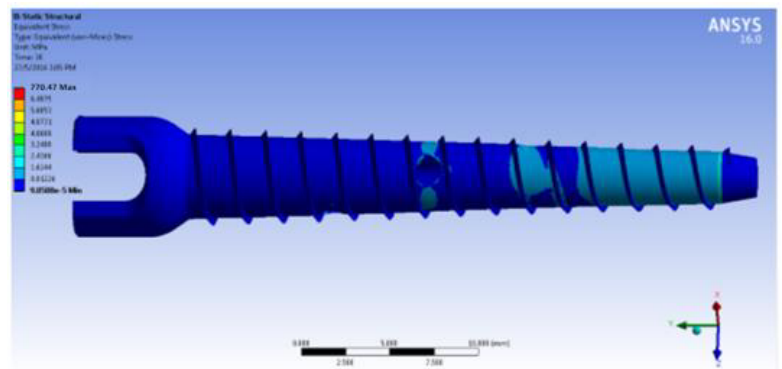

Figure 6. Equivalent Stress (Von Mises Stress) of CPS with 4 radial holes

\subsection{Radial hole row unilaterally}

From the FEA result (Figure 7)of this design shown that the highest allowable torque that the screw can bear is 3.2 $\mathrm{Nm}$ before it is approaching the yield strength of the CPS, 790Mpa (maximum Von Mises stress 778.51 MPa).

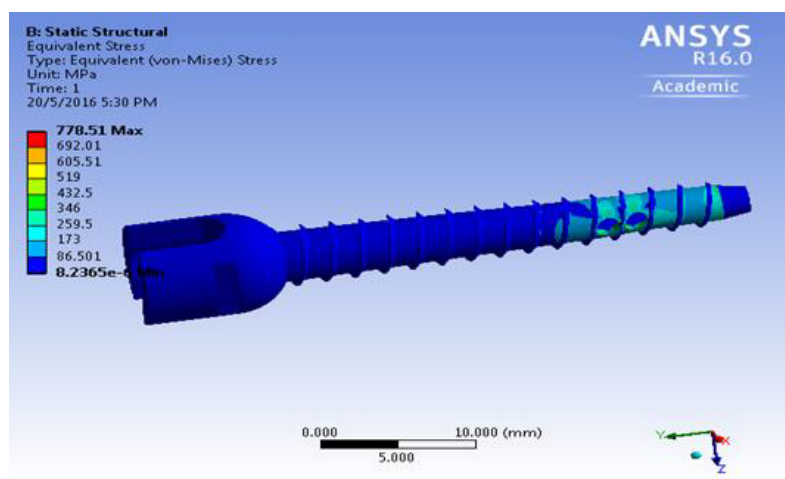

Figure 7. Equivalent Stress (Von Mises Stress) of CPS with 2 radial holes

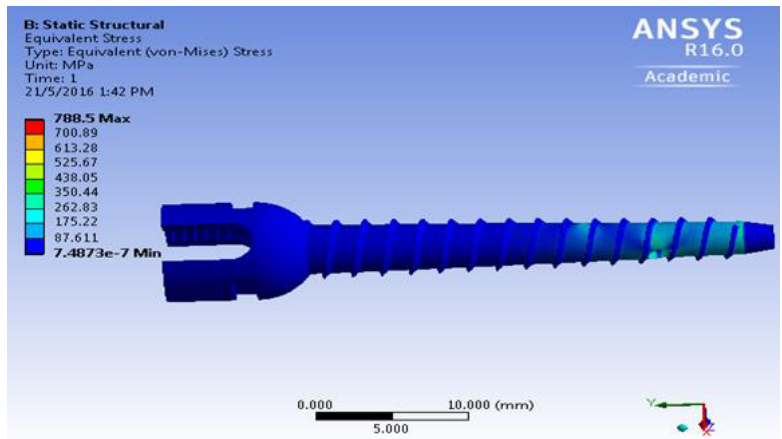

Figure 8. Equivalent Stress (Von Mises Stress) of CPS with 2 radial holes skewed to each other

\subsection{Proposed Design of CPS}

From the analysis, the results were obtained from the structural analysis for this design shown that the maximum stress with the highest torque of $3.92 \mathrm{Nm}$ applied is $788.5 \mathrm{MPa}$ (Figure 8). The highest allowable torque that the screw can bear is $3.92 \mathrm{Nm}$, and higher than that value, the deformation of the screw might be happen.

\subsection{Comparison Between the Current Designs and the Proposed Design}

In order to find the better design of CPS, each of the CPS is compared between each other in aspect of their maximum torque that can be applied. The detailed of the results obtained from the analysis is recorded as in Table 1 below.

Table 1. Moment and Maximum stress between the current design and the proposed design

\begin{tabular}{|c|c|c|c|c|c|}
\hline \multicolumn{4}{|c|}{$\begin{array}{l}\text { Current Design/Previous Research by } \\
\text { Chen at el. }\end{array}$} & \multirow{2}{*}{\multicolumn{2}{|c|}{$\begin{array}{c}\text { Proposed Design } \\
2 \text { Radial hole } \\
\text { positioned skewed } \\
\text { to each other }\end{array}$}} \\
\hline \multicolumn{2}{|c|}{$\begin{array}{l}4 \text { Radial hole } \\
\text { positioned } 90^{\circ} \text { to } \\
\text { each other }\end{array}$} & \multicolumn{2}{|c|}{$\begin{array}{l}2 \text { Radial hole row } \\
\text { unilaterally }\end{array}$} & & \\
\hline $\begin{array}{l}\text { Mome } \\
\mathrm{nt} \\
(\mathrm{Nm})\end{array}$ & $\begin{array}{c}\text { Maximu } \\
\mathrm{m} \text { Stress } \\
(\mathrm{MPa})\end{array}$ & $\begin{array}{c}\text { Mome } \\
\mathrm{nt} \\
(\mathrm{Nm})\end{array}$ & $\begin{array}{c}\text { Maximu } \\
\text { m Stress } \\
(\mathrm{MPa})\end{array}$ & $\begin{array}{c}\text { Mome } \\
\mathrm{nt} \\
(\mathrm{Nm})\end{array}$ & $\begin{array}{c}\text { Maximu } \\
\mathrm{m} \text { Stress } \\
(\mathrm{MPa})\end{array}$ \\
\hline 1.29 & 293.19 & 1.1 & 501.79 & 2 & 402.28 \\
\hline 1.59 & 361.37 & 1.4 & & 2.3 & \\
\hline 1.89 & 42 & 1.7 & & 2.6 & 98 \\
\hline 2.19 & 497.74 & 2 & & 2.9 & .33 \\
\hline 2.49 & 565.92 & 2.3 & 761.21 & 3.2 & 643.67 \\
\hline 2.79 & 634.1 & 2.6 & 769.86 & 3.5 & 704.01 \\
\hline 3.09 & & 2.9 & 775 & 3.8 & 764.36 \\
\hline 3.39 & 770.47 & 3.2 & 778.51 & 3.9 & 784.47 \\
\hline & & & & 3.92 & 788.5 \\
\hline
\end{tabular}

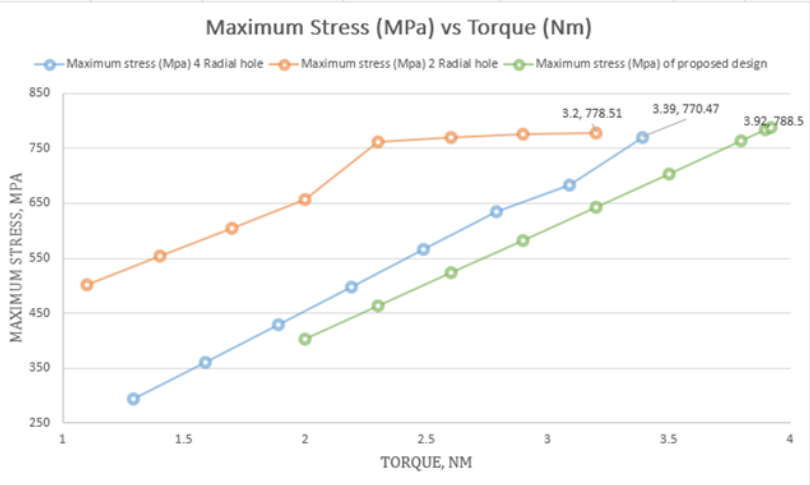

Figure 9. Comparison on the performance of CPS between the current designs and the proposed design.

From the results obtained, the recorded value of different moments that were applied on each design was then interpreted into the graph form as shown in the Figure 9. The red line on the graph represents current CPS designed with two radial hole row unilaterally while 
for the CPS with four radial hole positioned $90^{\circ}$ to each other descending counter clockwise according to the thread represented by blue line. Another one is the proposed design with two radial holes $(1 \mathrm{~mm})$ positioned skewed to each other represent by green line.

By referring to the graph, 2 radial holes row unilaterally shows the reading of the maximum stress (Von Mises Stress) of $778.51 \mathrm{MPa}$ with the highest applied moment of $3.2 \mathrm{Nm}$. Whereas the maximum stress (Von Mises Stress) reading for the 4 radial hole Cannulated Pedicle Screw is $770.47 \mathrm{MPa}$ with applied highest moment of $3.39 \mathrm{Nm}$. This is means, between this both design, CPS with 4 radial hole is better than 2 radial hole since the screw can bear the higher torque $3.39 \mathrm{Nm}$ and $3.2 \mathrm{Nm}$ respectively. However, among the three designs, the proposed design shows an improvement with the highest torque $(3.92 \mathrm{Nm})$ that can be applied before it fractures. It can be concluded that based on FEA results, the position and size of radial holes effect the performance of CPS where as the number of radial holes is not the factor that effected the performance of CPS same as reported by Chen at el. The research gap regarding on optimum of position and size of radial holes is closed since the proposed design with optimum position (2 radial holes skewed each other) and size of radial hole $(1.00 \mathrm{~mm}$ diameter) shown better performance of CPS than previous design by Chen at el.[3].

\section{References}

1. Tolunay, T., Arslan, K., Yaman, O., Dalbayrak, S., \& Demir, T. Biomechanical Performance of Various Cement-Augmented Cannulated Pedicle Screw Designs for Osteoporotic Bones. Spine Deformity, 3(3), 205-210 (2015)

2. B.E McKoy and Y. H An. An injectable cementing screw for fixation in osteoporotic bone. Journal of Biomedical Materials Research A, 53(3), 216-220 (2000)

3. Chen, H. C., Lai, Y. S., Chen, W. C., Chen, J. W., Chang, C. M., Chen, Y. L., Cheng, C. K.. Effect of different radial hole designs on pullout and structural strength of cannulated pedicle screws. Med Eng Phys, 37(8), 746-751 (2015)

4. Abshire BB, McLain RF, Valdevit A, Kambic HE. Characteristics of pullout failure in conical and cylindrical pedicle screws after full insertion and back out. Spine J 1:408-414 (2001)

5. Bianco RJ, Arnoux PJ, Mac-Thiong JM, Wagnac E, Aubin CE. Biomechanical analysis of pedicle screw pullout strength. Comput Methods Biomech Biomed Eng 16(Suppl 1):246-248 (2013)

6. Chao CK, Hsu CC, Wang JL, Lin J Increasing bending strength and pullout strength in conical pedicle screws: biomechanical tests and finite element analyses. J Spinal Disord Tech 21(2):130138 (2008)

7. Chao KH, Lai YS, Chen WC, Chang CM, McClean CJ, Fan CY, et al. Biomechanical analysis of different types of pedicle screw augmentation: cadaveric and synthetic bone sample study of instrumented vertebral specimens. Med Eng Phys.35:1506-12. (2013)

8. Chatzistergos PE, Magnissalis EA, Kourkolis SK A. parametric study of cylindrical pedicle screw design implications on the pullout performance using an experimentally validated finite element model. Med Eng Phys 32:145-154 (2010)

9. Paré, P. E., Chappuis, J. L., Rampersaud, R., Agarwala, A. O., Perra, J. H., Erkan, S., \& Wu, C. Biomechanical evaluation of a novel fenestrated pedicle screw augmented with bone cement in osteoporotic spines. Spine, 36(18), E1210-E1214 (2011).

10. Patel, R. D., Graziano, G. P., Vanderhave, K. L., Patel, A. A., \& Gerling, M. C. Facet. Violation With the Placement of Percutaneous Pedicle Screws. Spine, 36(26), E1749-E1752 (2011) 